\title{
Assessing the effect of traditional chinese medicine on CD4+ lymphocyte count of 807 HIV/AIDS cases*
}

\author{
Jian Wang ${ }^{1}$, Wen Zou ${ }^{1}$, Ying Liu ${ }^{1}$, Liran Xu ${ }^{2}$, Fang Lu ${ }^{3}$, Yuguang Wang ${ }^{4}$, Guoliang Zhang ${ }^{5}$, \\ Jiaming Lu ${ }^{1}$, Jun Zhou ${ }^{1}$
}

${ }^{1}$ Traditional Chinese Medicine Center for AIDS Prevention and Treatment, China Academy of Chinese Medicine Sciences, Beijing, China;

${ }^{2}$ Henan Academy of Traditional Chinese Medicine, Zhengzhou, China;

${ }^{3}$ Yunnan Academy of Traditional Chinese Medicine, Kunming, China;

${ }^{4}$ Beijing Ditan Hospital, Beijing, China;

${ }^{5}$ An’hui Hospital of Traditional Chinese Medicine, Hefei, China.

Email: veven@yeah.net

Received 20 May 2010; revised 8 June 2010; accepted 21 June 2010.

\begin{abstract}
National Free Traditional Chinese Medicine (TCM) HIV/AIDS Treatment Program had been carried out for more than 5 years, treating 9267 cases accumulately by 2009. We report the 3-year outcome on CD4+ lymphocyte count of $\mathbf{8 0 7}$ cases of HIV/AIDS enrolled in the National Free TCM HIV/AIDS Treatment Program, the CD4+ lymphocyte count were measured every 6 month at 7 time points $(0,6,12,18,24,30,36$ month). The results showed that the overall CD4+ ly mphocyte count maintained stable at the 6th month and the 12th month, declined significantly at the 18th month, 24th month and 30th month, then elevated to the pre-treatment level at the 36th month. Patients with pre-treatment CD4+ lymphocyte count level < 200/ $\mathrm{mm}^{3}$, who possibly combined HAART therapy, had CD4+ lymphocyte count elevated significantly after all visits. Patients with pre-treatment CD4+ lymphocyte count level between 200 and $350 / \mathrm{mm}^{3}$ maintained stable before the 36 th month, and then rosed significantly, which implicated the long-term effect of TCM. Patients with pre-treatment CD4+ lymphocyte count level $>350 / \mathrm{mm}^{3}$ had CD4+ lymphocyte count declined significantly after all visits. In summary, combined treatment of Chinese herbal medicine and conventional therapy on HIV/AIDS suggested promising effect, but more evidences from larger, rigorous designed studies still needed to support the affirmative effect of TCM in the future.
\end{abstract}

*Granted Fund: State Major Science \& Technology Specific Projects (2008ZX10005-001).
Keywords: Traditional Chinese Medicine; HIV/AIDS; CD4+ lymphocyte count

\section{INTRODUCTION}

In China, an estimated 740,000 persons are infected with HIV, of whom approximately 105,000 have developed AIDS [1]. Of these, a cumulative of 319,877 patients, had been identified as of October 2009 [2]. Before 2002, when China initiated its National Free Antiretroviral Treatment Program as a pilot project among former plasma donors [3,4], antiretroviral therapy (ART) was not readily available. Treatment was rapidly scaled up, and by August 2008, more than 52,000 persons had received first-line highly active antiretroviral therapy (HAART). Traditional Chinese Medicine (TCM) intervention started from 2004, a pilot project named National Free TCM HIV/AIDS Treatment Program had been launched by The State Administrative bureau of Traditional Chinese Medicine, and quickly scaled up from 5 provinces (Henan, Hebei, Anhui, Hubei, Guangdong) to 19 provinces, autonomous regions, and municipalities in China including some places with high prevalence, 9267 cases have been treated with TCM accumulatively by 2009 .

HIV weakens the immune system by attacking CD4 lymphocyte count, CD4 lymphocyte count is a strong predictor of assessing prognosis of AIDS. [5,6].

We report the 3-year outcome on CD4+ lymphocyte count of 807 cases of HIV/AIDS enrolled in the National Free TCM HIV/AIDS Treatment Program by retrospective analysis, the CD4+ lymphocyte count were measured every 6 month at 7 time points $(0,6,12,18,24$, 30, 36 month). 


\section{METHOD}

\subsection{Study Design and Setting}

In China, all HIV-positive patients who meet the national treatment guidelines of CD4+ lymphocyte count less than $0.200 \times 10^{9}$ cells $/ \mathrm{L}$, total lymphocyte count less than $1.2 \times 10^{9}$ cells/L, or World Health Organization (WHO) stage 3 or 4 disease are eligible to receive HAART[7].When National Free TCM HIV/AIDS Treatment Program launched by 2004, HIV-positive patients who were willing to receive TCM can be enrolled in TCM program, no matter its CD4+ lymphocyte count levels. After treatment initiation, visits are scheduled at 6 month, 12 months, 18 months, and then every 6 months thereafter. Local TCM health care providers from the program complete visit-specific forms at each visit, all the information was imputed into the database. We selected 807 cases from the database which had good TCM compliance. $80 \%$ of them were paid blood donors from Henan Province with average age at 41. Male 377, female 430, 222 cases of them had combined with HAART therapy. Chinese herb medicine adopted prescriptions according to syndrome differentiation or patent used by local doctors from each province.

\subsection{Statistical Analysis}

T-Test statistic was used in this study for quantitative variables. SPSS, version 13.0 (SPSS, Chicago, Illinois), and SAS, version 9.13 (SAS Institute, Cary, North Car- olina), was used for all analyses. All hypothesis testing was 2-sided, with an a level of 0.05.

\section{RESULTS}

\subsection{CD4+ Lymphocyte Count Overall Variation}

The CD4+ lymphocyte count maintained stable at the 6th month and 12th month, declined significantly at the 18th month, 24th month and 30th month, then elevated to the pre-treatment level at 36th month (Table 1).

\subsection{CD4+ Lymphocyte Count Variations by Different Pre-Treatment Level}

Patients with pre-treatment CD4+ lymphocyte count level $<200 / \mathrm{mm}^{3}$, who possibly combined HAART therapy, had CD4+ lymphocyte count elevated significantly after all visits (Table 2). Patients with pre-treatment CD4+ lymphocyte count level between 200 and $350 / \mathrm{mm}^{3}$ maintained stable before 36 months, and then rose significantly (Table 3), which implicated the long-term effect of TCM. Patients with pre-treatment CD4+ lymphocyte count level $>350 / \mathrm{mm}^{3}$, had CD4+ lymphocyte count declined significantly after all visits (Table 4).

\subsection{CD4+ Lymphocyte Count Variations by Different Clinical Stages}

CD4+ lymphocyte count of patients at both stage maintained stable at all visits which may implicated TCM effect (see Table 5,6).

Table 1. CD4+ lymphocyte count overall variation pre-post TCM treatment (/mm $3 \mathrm{~m}^{3}$.

\begin{tabular}{|c|c|c|c|c|c|}
\hline months & case & $\begin{array}{c}\text { pre } \\
(\bar{x} \pm s)\end{array}$ & $\begin{array}{c}\text { post } \\
(\bar{x} \pm s)\end{array}$ & t-test & $P$ \\
\hline 0 & 807 & $340.42 \pm 202.14$ & & & \\
\hline 6 & 129 & & $296.10 \pm 159.47$ & -0.303 & $<0.763$ \\
\hline 12 & 365 & & $324.81 \pm 311.76$ & -1.688 & $<0.092$ \\
\hline 18 & 426 & & $287.34 \pm 168.49$ & 3.141 & $<0.002$ \\
\hline 30 & 384 & & $298.40 \pm 175.26$ & 2.478 & $<0.014$ \\
\hline 36 & 807 & & $346.02 \pm 231.11$ & -0.885 & $<0.377$ \\
\hline
\end{tabular}

Table 2. CD4+ lymphocyte count variation with pre-treatment level $<200\left(/ \mathrm{mm}^{3}\right)$.

\begin{tabular}{|c|c|c|c|c|c|}
\hline months & case & $\begin{array}{c}\text { pre } \\
(\bar{x} \pm s)\end{array}$ & $\begin{array}{c}\text { post } \\
(\bar{x} \pm s)\end{array}$ & t-test & $P$ \\
\hline 0 & 210 & $120.56 \pm 55.63$ & & & \\
\hline 6 & 37 & & $207.00 \pm 160.12$ & -3.597 & $<0.001$ \\
\hline 12 & 110 & & $234.42 \pm 151.61$ & -8.527 & $<0.000$ \\
\hline 18 & 116 & & $199.53 \pm 143.60$ & -5.832 & $<0.000$ \\
\hline 24 & 114 & & $222.88 \pm 171.35$ & -6.055 & $<0.000$ \\
\hline 30 & 84 & & $196.41 \pm 121.02$ & -5.521 & $<0.000$ \\
\hline 36 & 210 & & $249.69 \pm 188.67$ & -9.656 & $<0.000$ \\
\hline
\end{tabular}


Table 3. CD4+ lymphocyte count variation with pre-treatment level between 200-350 (/mm $\left.{ }^{3}\right)$.

\begin{tabular}{|c|c|c|c|c|c|}
\hline months & case & $\begin{array}{c}\text { pre } \\
(\bar{x} \pm s)\end{array}$ & $\begin{array}{c}\text { post } \\
(\bar{x} \pm s)\end{array}$ & t-test & $P$ \\
\hline 0 & 258 & $276.53 \pm 43.14$ & & & \\
\hline 6 & 38 & & $282.15 \pm 104.19$ & -0.076 & $<0.940$ \\
\hline 12 & 105 & & $318.19 \pm 470.41$ & -1.018 & $<0.311$ \\
\hline 18 & 130 & & $274.20 \pm 128.30$ & 0.163 & $<0.871$ \\
\hline 24 & 151 & & $269.90 \pm 147.63$ & 0.768 & $<0.444$ \\
\hline 30 & 119 & & $285.06 \pm 144.18$ & -0.175 & $<0.862$ \\
\hline 36 & 258 & & $307.13 \pm 182.81$ & -2.635 & $<0.009$ \\
\hline
\end{tabular}

Table 4. CD4+ lymphocyte count variation with pre-treatment level between > $350\left(/ \mathrm{mm}^{3}\right)$.

\begin{tabular}{|c|c|c|c|c|c|}
\hline months & case & $\begin{array}{c}\text { pre } \\
(\bar{x} \pm s)\end{array}$ & $\begin{array}{c}\text { post } \\
(\bar{x} \pm s)\end{array}$ & t-test & $P$ \\
\hline 0 & 339 & $525.24 \pm 163.42$ & & & \\
\hline 6 & 34 & & $389.67 \pm 171.40$ & 3.553 & $<0.001$ \\
\hline 12 & 118 & & $434.23 \pm 235.69$ & 3.331 & $<0.001$ \\
\hline 18 & 139 & & $377.65 \pm 183.26$ & 9.093 & $<0.000$ \\
\hline 24 & 152 & & $338.47 \pm 181.27$ & 10.227 & $<0.000$ \\
\hline 30 & 127 & & $392.29 \pm 195.24$ & 6.909 & $<0.000$ \\
\hline 36 & 339 & & $440.10 \pm 257.09$ & 6.074 & $<0.000$ \\
\hline
\end{tabular}

Table 5. CD4+ lymphocyte count variation of patients at asymptomatic stage $\left(/ \mathrm{mm}^{3}\right)$.

\begin{tabular}{|c|c|c|c|c|c|}
\hline months & case & $\begin{array}{c}\text { pre } \\
(\bar{x} \pm s)\end{array}$ & $\begin{array}{c}\text { post } \\
(\bar{x} \pm s)\end{array}$ & t-test & $P$ \\
\hline 0 & 513 & $367.54 \pm 216.48$ & & & \\
\hline 6 & 62 & & $289.62 \pm 179.22$ & -0.671 & $<0.505$ \\
\hline 12 & 213 & & $359.63 \pm 381.49$ & -0.961 & $<0.338$ \\
\hline 18 & 232 & & $302.64 \pm 174.12$ & 3.383 & $<0.001$ \\
\hline 24 & 257 & & $288.39 \pm 176.62$ & 4.033 & $<0.000$ \\
\hline 30 & 202 & & $322.99 \pm 188.09$ & 2.042 & $<0.043$ \\
\hline 36 & 499 & & $363.96 \pm 250.55$ & 0.383 & $<0.702$ \\
\hline
\end{tabular}

Table 6. CD4+ lymphocyte count variation of patients at AIDS stage $\left(/ \mathrm{mm}^{3}\right)$.

\begin{tabular}{|c|c|c|c|c|c|}
\hline months & case & $\begin{array}{c}\text { pre } \\
(\bar{x} \pm s)\end{array}$ & $\begin{array}{c}\text { post } \\
(\bar{x} \pm s)\end{array}$ & t-test & $P$ \\
\hline 0 & 294 & $285.99 \pm 162.30$ & & & \\
\hline 6 & 47 & & $286.74 \pm 136.31$ & 0.066 & $<0.948$ \\
\hline 12 & 116 & & $279.72 \pm 159.36$ & -2.793 & $<0.006$ \\
\hline 18 & 149 & & $264.55 \pm 161.55$ & 0.254 & $<0.800$ \\
\hline 24 & 156 & & $268.32 \pm 161.83$ & 1.282 & $<0.202$ \\
\hline 30 & 125 & & $269.24 \pm 155.85$ & 1.078 & $<0.283$ \\
\hline 36 & 308 & & $319.32 \pm 198.79$ & -2.828 & $<0.005$ \\
\hline
\end{tabular}

\section{DISCUSSION}

It has been 23 years since Chinese government sent TCM doctors to aid Tanzania HIV/AIDS patients, therapeutic effect has been achieved through ten thousands of accumulative Tanzania HIV/AIDS cases. It was reported that 23 cases of Tanzania patients with more than 10 years HIV/AIDS history maintained their CD4+ lymphocyte count stable around $350 / \mathrm{mm}^{3}$ by use of TCM[8]. Experimental study also showed that Chinese herb compound prescription ZY-1 may help activation and hyperplasia of CD4 cell in lymph nodes [9]. 
In our study, the overall CD4+ lymphocyte count maintained stable at the 6th month and 12th month, declined significantly at 18th month, 24th month and 30th month, then elevated to the pre-treatment level at 36th month, which was in accordance with the result of clinical trial conducted by Wang Jian et al. In that trial, CD4 count decreased in both groups (Aining granule + HAART; placebo + HAART) after 11 months treatment, the decrease of mean value of CD4 was significantly less in the Aining group $\left(-87.65 \pm 107.98 / \mathrm{mm}^{3}\right)$ than in the control group $\left(-156.51 \pm 157.04 / \mathrm{mm}^{3}, \mathrm{P}<0.05\right)$ [10].

By analysis of database, Patients with pre-treatment CD4+ lymphocyte count level $<200 / \mathrm{mm}^{3}$, who possibly combined HAART therapy, had CD4+ lymphocyte count elevated significantly after all visits. Patients with pre-treatment CD4+ lymphocyte count level between 200 and $350 / \mathrm{mm}^{3}$ maintained stable before 36 months, and then rose significantly, which implicated the longterm effect of TCM. Patients with pre-treatment CD4+ lymphocyte count level $>350 / \mathrm{mm}^{3}$ had CD4+ lymphocyte count declined significantly after all visits.

In summary, combined treatment of Chinese herbal medicine of HIV/AIDS suggested promising effect, but more evidence from larger, rigorous designed studies still needed to support the affirmative effect of TCM in the future.

\section{REFERENCES}

[1] Wang, L., Wang, N., Wang, L., Li, D., Jia, M., Gao, X., et al. (2009) The 2007 estimates for people at risk for and living with HIV in China: Progress and challenges. Journal of Acquired Immune Deficiency Syndromes, 50(4), 414-418.

[2] State Council AIDS Working Committee Office, UN.
Theme Group on AIDS in China. A Joint Assessment of HIV/AIDS Prevention, Treatment and Care in China. Ministry of Health, Beijing, China, 2007.

[3] Zhang, F.J., Pan, J., Yu, L., et al. (2005) Current progress of China's free ART program. Cell Research, 15(11-12), 877-882.

[4] Zhang, F., Haberer, J.E., Wang, Y., et al. (2007) The Chinese free antiretroviral treatment program: Challenges and responses. Acquired Immune Deficiency Syndrome, 21(Suppl 8), 143-148.

[5] Fahey, J.L., Taylor, J.M., Manna, B., et al. (1998) Prognostic significance of plasma markers of immune activation, HIV viral load and CD4 T-cell measurements. Acquired Immune Deficiency Syndrome, 12(13), 15811590.

[6] Vlahov, D., Graham, N., Hoover, D., et al. (1998) Prognostic indicators for AIDS and infectious disease death in HIV-infected injection drug users: Plasma viral load and CD4+ cell count. Joint Admission Test for Msc, 159, 35-40.

[7] Chinese Center for Disease Control and Prevention. China Free ART Manual. Ministry of Health, Beijing, China, 2005.

[8] Wei, J.N., Sun, L.M., Lv, W.B., et al. (2005) HIV/AIDS case report with TCM treatment lasted for 10 years. Journal of Traditional Chinese Medicine, 46, 829-831.

[9] Guan, C.F., Wu, X.X., Lu, Y.Z., et al. (1995) Experimental study of monkey model of AIDS with Zhongyan. Chinese Journal of Information on TCM, 2, 42-46.

[10] Wang, J., Liu, Y.,and Zou, W. (2008) Clinical observations on $100 \mathrm{HIV} / \mathrm{AIDS}$ cases treated with Chinese herb aining granule plus HAART. Chinese Journal of AIDS \& STD, 14, 101-107. 